\title{
PWM Boost Converter Integrating Differential Power Processing Converter to Enhance Energy Yield of Photovoltaic Panels Under Characteristic Mismatch Conditions
}

\author{
Masatoshi Uno ${ }^{* a)}$ Member, Yusuke Sasaki ${ }^{*}$ Student Member \\ (Manuscript received July 6, 2020, revised Sep. 15, 2020) \\ J-STAGE Advance published date : Oct. 23, 2020
}

\begin{abstract}
Partial shading on a photovoltaic (PV) panel consisting of multiple substrings is known to trigger a significant reduction in energy yield and the occurrence of multiple maximum power points (MPPs), including one global and multiple local MPPs. Uneven irradiance on curved PV panels, such as flexible panels and solar roofs of electric vehicles, also causes characteristic mismatch, triggering the same issues. Although various types of differential power processing (DPP) converters have been proposed to preclude the characteristic mismatch issues, the DPP converter is separately required in addition to an existing boost converter for panel control, resulting in increased system complexity, cost, and volume. This study proposes a novel integrated converter that realizes system simplification and circuit miniaturization by integrating a PWM boost and a DPP converter into a single unit. Laboratory and field tests were performed emulating partial shading and characteristic mismatch conditions. The proposed converter eliminated local MPPs and increased maximum power while boosting the panel voltage, demonstrating the efficacy of the proposed integrated converter.
\end{abstract}

Keywords: differential power processing converter, integrated converter, uneven irradiance, photovoltaic panel, PWM boost converter

\section{Introduction}

Partial shading on photovoltaic (PV) panels comprising multiple substrings connected in series causes a significant mismatch in substring characteristics, as shown in Fig. 1(a). The shaded substring, which is less capable of producing current, is bypassed by a parallel-connected bypass diode, and its voltage becomes subzero. The shaded substring no longer contributes to power generation, resulting in a significant reduction in the energy yield of the panel as a whole ${ }^{(1)}$. Furthermore, $P-V$ characteristics of the panel exhibit multiple maximum power point (MPPs), including one global and multiple local MPPs, as shown in Fig. 1(b). In general, an MPP tracking control is performed to maximize energy yield in PV systems, but the panel might operate at a local MPP that is a suboptimal point producing less power than the global MPP.

These negative influences originate from the electrical characteristic mismatch of substrings. Similar characteristic mismatch situations likely happen in various applications. In PV panels mounted on electric vehicles' roof, for example, substring characteristics are always mismatched to some extent due to uneven irradiance on the curved roof, as illustrated in Fig. 1(c) ${ }^{(2)}$. Another example is a flexible PV panel that is used on curved surfaces.

To cope with such problems, various kinds of differential power processing (DPP) converters, also known as voltage

\footnotetext{
a) Correspondence to: Masatoshi Uno. E-mail: masatoshi.uno.ee @vc.ibaraki.ac.jp

* Ibaraki University

4-12-1, Nakanarusawa, Hitachi, Ibaraki 316-8511, Japan
}

equalizers, have been proposed ${ }^{(3)}$. DPP converters transfer a fraction of generated power from unshaded substrings to shaded ones so that all substrings operate at the same voltage or even at each MPP. DPP converters can be categorized into several architectures, depending on power redistribution scenarios, as listed in Fig. 2.

The most straightforward architecture is the adjacent substring-to-substring topologies based on non-isolated bidirectional converters, such as PWM converters ${ }^{(4)-(1)}$ and switched capacitor converters ${ }^{(12)-(19)}$. With these topologies, adjacent two substrings exchange power under partial shading conditions. The panel-to-bus or panel-to-virtual bus architectures rely on isolated bidirectional flyback converters to transfer power among substrings ${ }^{(20)-(26)}$. These architectures are often employed thanks to their topology popularity, but each DPP converter requires at least two switches and one flyback transformer. In addition, the number of DPP converters necessary is proportional to the number of substrings, hence resulting in increased system complexity and cost.

Meanwhile, the panel-to-substring DPP converter architecture can dramatically reduce not only the switch count but also the number of DPP converters necessary in the system $^{(27)-(31)}$. These panel-to-substring DPP converters are based on single-input-multi-output converters, such as multiwinding flyback converter ${ }^{(27)}$, multi-stacked buck-boost converter ${ }^{(28)(29)}$, and LLC resonant voltage multiplier (VM) ${ }^{(30)(31)}$.

The conventional LLC-VM for three substrings are shown in Fig. 3, as a representative topology. There are only two switches, regardless of the number of substrings. This DPP converter redistributes power from the panel to shaded 


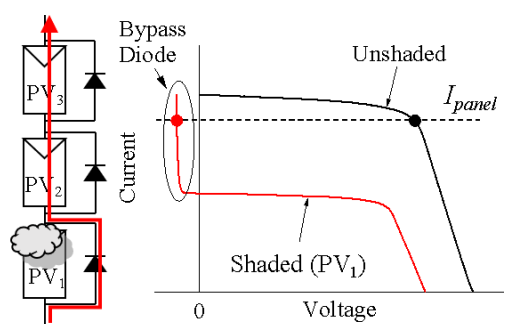

(a)

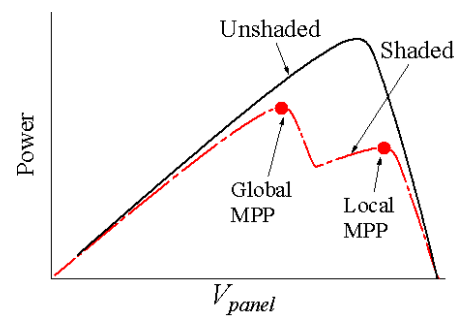

(b)

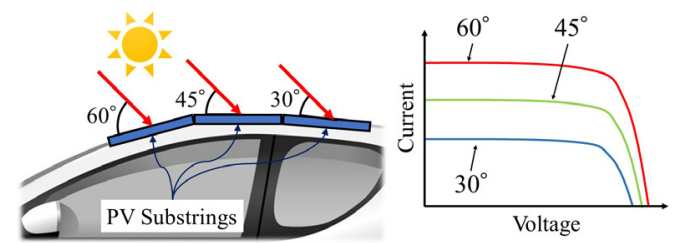

(c)

Fig. 1. (a) Substring characteristics and (b) panel characteristics under partial shading. (c) Characteristic mismatch due to uneven irradiance on solar roof

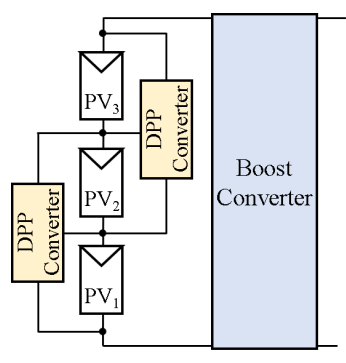

(a)

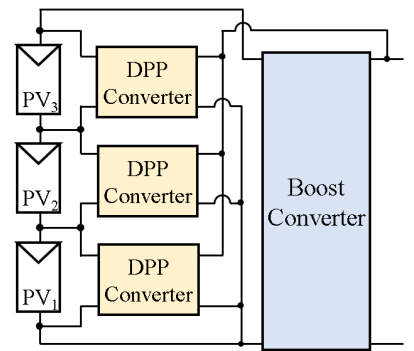

(c)

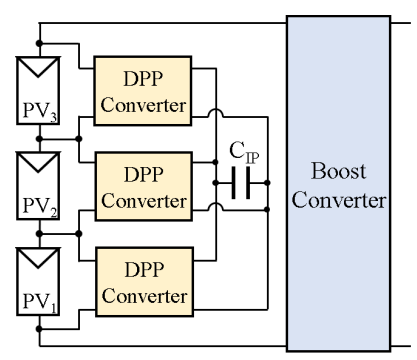

(b)

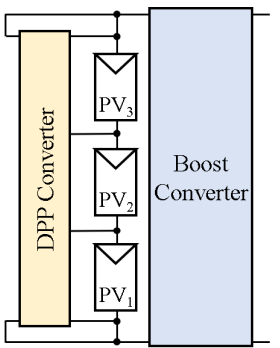

(d)
Fig. 2. DPP converter architectures. (a) Adjacent substring-to-substring, (b) panel-to-virtual bus, (c) panelto-bus, (d) panel-to-substring architectures

substrings having the lowest voltage even without feedback control. All substring voltages or characteristics are nearly unified, and the negative influences of partial shading are automatically precluded.

Meanwhile, a boost converter is generally indispensable to bridge the voltage gap between PV panels and loads. Since a DPP converter and a boost converter are separately required, conventional PV systems are prone to complexity, as shown

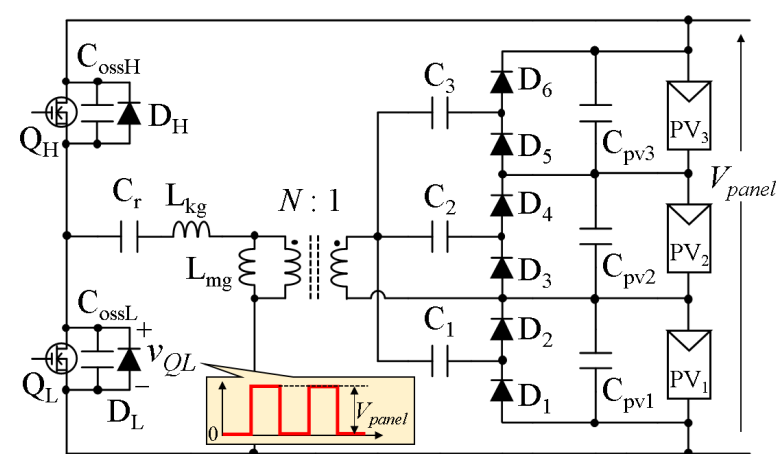

Fig. 3. Conventional panel-to-substring DPP converter based on LLC voltage multiplier.

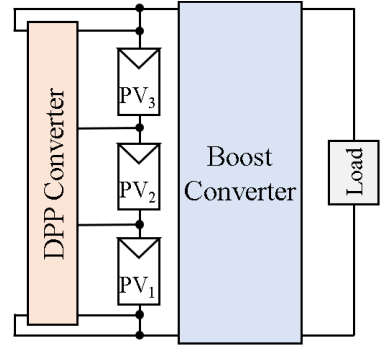

(a)

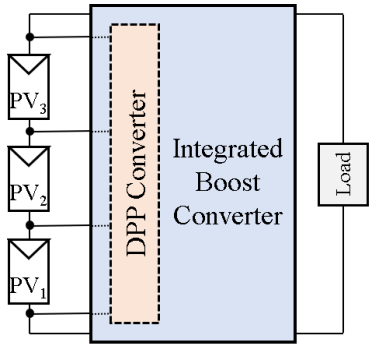

(b)
Fig. 4. (a) Conventional PV system with separate boost converter and DPP converter. (b) Proposed system integrating boost converter and DPP converter

in Fig. 4(a). If the boost converter and DPP converter were to be integrated into a single unit with reducing circuit components, the PV system and converter circuit would be even simpler and less expensive.

This paper proposes a novel PWM boost converter integrating the DPP converter. A PWM boost converter and LLCVM-based DPP converter are integrated into a single unit with sharing switches, hence reducing the system and circuit complexity-the notional system is shown in Fig. 4(b). Similar to the conventional LLC-VM, the DPP converter nearly unifies substring voltages or characteristics without feedback control.

This paper is organized as follows. Section 2 describes the proposed integrated converter and its major features, followed by the operation analysis in Section 3. Section 4 presents experimental results of laboratory and field testing for four substrings connected in series under partial shading and characteristic mismatched conditions, respectively.

\section{Proposed Integrated PWM Boost Converter}

2.1 Circuit Description The proposed integrated PWM boost converter for three substrings is shown in Fig. 5. The proposed converter is derived from the combination of the conventional LLC-VM-based DPP converter $^{(30)}$ and the PWM boost converter containing a flying capacitor $\mathrm{C}_{\mathrm{f}}$. These converters are integrated by sharing switches of $\mathrm{Q}_{\mathrm{L}}$ and $\mathrm{Q}_{\mathrm{H}}$. The key concept of the integration is that the LLC-VM is driven by a square wave voltage generated at the switching node or the voltage across $\mathrm{Q}_{\mathrm{L}}, v_{Q L}$.

One might consider that a traditional boost converter could be a foundation circuit for the integrated converter, but not recommended for the integration. A peak-to-peak voltage 


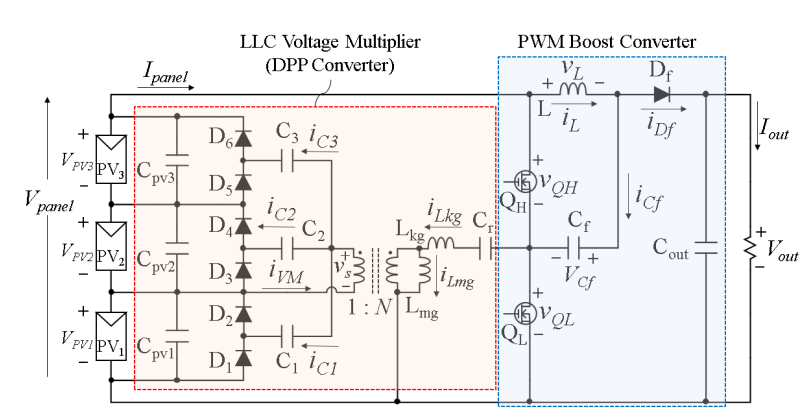

Fig. 5. Proposed PWM boost converter integrating LLC-VM-based DPP converter for three substrings
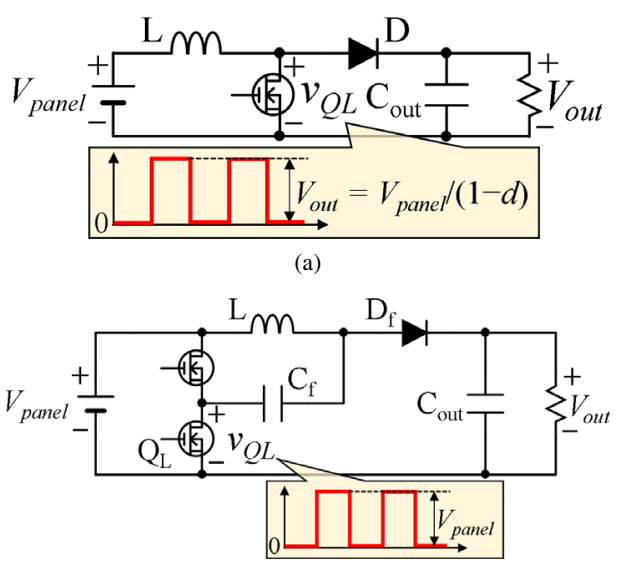

(b)

Fig. 6. Boost converter topologies and their square wave voltage generated at switching node. (a) Traditional boost converter. (b) Boost converter with a flying capacitor

generated at a switching node in the traditional boost converter is equal to an output voltage $V_{\text {out }}=V_{\text {panel }} /(1-d)$ (where $d$ is the duty cycle), as shown in Fig. 6(a). Since the LLC-VM is driven by $v_{Q L}$ with a peak-to-peak voltage of $V_{\text {out }}$, output voltages of the LLC-VM (i.e., voltages of $\mathrm{C}_{\mathrm{pv} 1}-\mathrm{C}_{\mathrm{pv} 3}$ ) vary with $d$. In such a case, the LLC-VM would provide insufficient currents to shaded substrings or unnecessarily supply excessive currents to unshaded substrings. With the boost converter for the proposed integrated converter [see Fig. 6(b)], on the other hand, a peak-to-peak voltage at a switching node is always $V_{\text {panel }}$ and is independent on $V_{\text {out }}$. Hence, similar to the conventional LLC-VM, the LLC-VM is driven by $v_{Q L}$ with a peak-to-peak voltage $V_{\text {panel }}$, realizing the automatic preclusion of characteristic mismatch issues without feedback control.

2.2 Features The conventional PV system using a DPP converter and traditional PWM boost converter separately [see Fig. 4(a)] requires three switches in total; two and one switches in the DPP and boost converters, respectively. The proposed integrated converter, on the other hand, can reduce the total switch count as low as two, in addition to the reduced system complexity by integrating two converters (i.e., the boost converter and DPP converter) into a single unit.

The flying capacitor $\mathrm{C}_{\mathrm{f}}$ contributes to the miniaturization of the inductor L compared with that in a traditional PWM boost converter. $C_{f}$ not only reduces the applied voltage across $\mathrm{L}$ but also processes a fraction of the total output

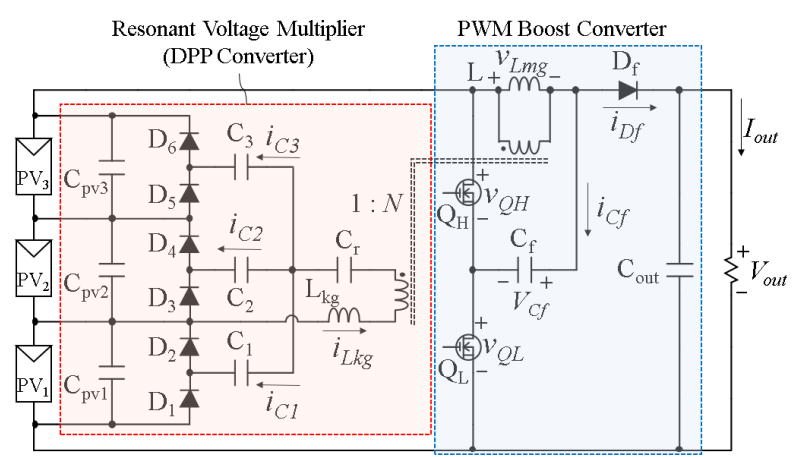

(a)

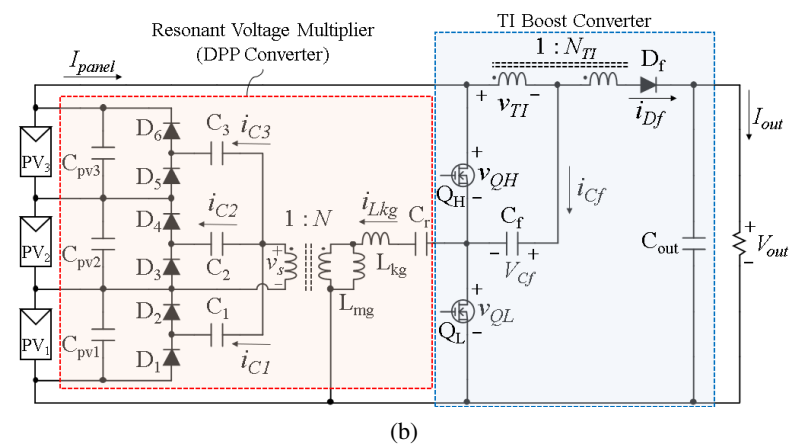

Fig. 7. Extended topologies of proposed integrated converter. (a) Integrated converter with integrated magnetic component. (b) Integrated converter with tapped inductor

power, as will be detailed in Section 3.3. The added $\mathrm{C}_{\mathrm{f}}$ has a very tiny impact on the circuit volume because an energy density of discrete capacitors is generally within three orders of magnitude over that of similarly scaled inductors ${ }^{(32)(33)}$.

In summary, the proposed integrated converter realizes the system simplification and circuit miniaturization by integrating two converters into a single unit while achieving the reduction of the switch count and inductor miniaturization.

A narrower boost conversion range should be cited as a drawback. The boost conversion ratio of the proposed converter is theoretically $1+d$ and is rather narrower than that of traditional boost converter [i.e., $1 /(1-d)$ ]. The conversion range can be extended by employing a tapped inductor (TI) in an extended topology, as will be introduced in the following subsection.

Another drawback is that the performance of the DPP converter (i.e., the LLC-VM) in the integrated converter cannot be optimized because of the integration. An optimal $d$ of the LLC-VM is $50 \%$, but $d$ is determined by the voltage conversion ratio of the PWM boost converter. Hence, the proposed integrated converter is considered best suitable for applications where the system simplification and cost reduction are prioritized over performance optimization.

2.3 Extended Topologies Two magnetic components (i.e., the inductor and transformer) can be integrated by properly utilizing a leakage and magnetizing inductances of a transformer, further miniaturizing the circuit, as shown in Fig. 7(a). The resonant capacitor, $\mathrm{C}_{\mathrm{r}}$, is placed on the VMside in order not to block dc current component in the PWM boost converter.

Various kinds of high step-up converters with a tapped inductor (TI) have been proposed for renewable energy sources ${ }^{(34)(35)}$. Similar to conventional boost converters, a 
TI can be introduced in the proposed integrated converter to achieve a higher step-up conversion ratio, as shown in Fig. 7(b).

\section{Operation Analysis}

3.1 Operation Mode The operation analysis is performed with the premise that a forward voltage drop of $\mathrm{D}_{\mathrm{f}}$ is zero, and the capacitance of $\mathrm{C}_{\mathrm{f}}$ is large enough so that its voltage $V_{C f}$ is constant. All circuit elements are assumed ideal unless otherwise noted. Deadtime periods are neglected. The transformer winding connected to the resonant capacitor $C_{r}$ is defined as the primary side, and the opposite side is defined as the secondary side.

Characteristic mismatch conditions vary depending on seasons, time, locations, etc. This section takes a representative case that $\mathrm{PV}_{3}$ only is partially shaded. Key operation waveforms and current flow directions are shown in Figs. 8 and 9, respectively.

Mode $1\left(0<t \leq T_{1}\right)$ [Fig. 9(a)]: $\mathrm{Q}_{\mathrm{L}}$ and $\mathrm{Q}_{\mathrm{H}}$ are turned on and off, respectively. The voltage of $\mathrm{L}, v_{L}$, is $V_{\text {panel }}-V_{C f}$. The current of $\mathrm{L}, i_{L}$, linearly increases, and $\mathrm{C}_{\mathrm{f}}$ is charged. The input voltage of the LLC-VM or $v_{Q L}$ is zero. $\mathrm{L}_{\mathrm{kg}}$ and $\mathrm{C}_{\mathrm{r}}$ resonate, and the current of $\mathrm{L}_{\mathrm{kg}}, i_{L k g}$, sinusoidally changes. Meanwhile, the current of $\mathrm{L}_{\mathrm{mg}}, i_{L m g}$, linearly decreases. The difference between $i_{L k g}$ and $i_{L m g}$ is transferred to the secondary side in the form of $i_{V M}$ and flows through the coupling capacitor $\mathrm{C}_{3}$ and the low-side diode $\mathrm{D}_{5}$. The operation moves to the next mode when $i_{L k g}$ becomes equal to $i_{L m g}$.

Mode $2\left(T_{1}<t \leq T_{2}\right)$ [Fig. 9(b)]: $i_{L k g}$ and $i_{L m g}$ are equal and linearly decrease, while no current flows on the secondary side. In other words, the VM is inactive in this mode. The operation of the PWM boost converter in this mode is identical to that in Mode 1.

Mode 3 ( $T_{2}<t \leq T_{3}$ ) [Fig. 9(c)]: $\mathrm{Q}_{\mathrm{L}}$ and $\mathrm{Q}_{\mathrm{H}}$ are turned off and on, respectively, and the diode $\mathrm{D}_{\mathrm{f}}$ conducts. $v_{L}$ becomes $V_{\text {panel }}-V_{\text {out }}$, and its voltage polarity is reversed. $i_{L}$ starts linearly decreasing, and $\mathrm{C}_{\mathrm{f}}$ is discharged. It is noteworthy that

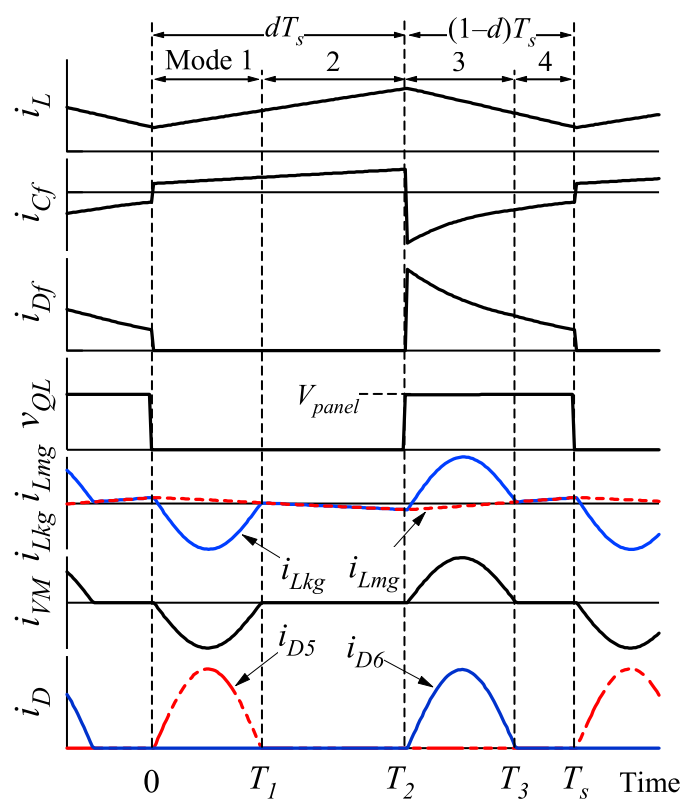

Fig. 8. Theoretical key operation waveforms when $\mathrm{PV}_{3}$ is partially shaded
$i_{L}$ as well as $i_{C}$ flow toward the load through $\mathrm{D}_{\mathrm{f}} . \mathrm{C}_{\mathrm{f}}$ is sandwiched by two voltage sources of $V_{\text {in }}$ and $V_{\text {out }}$, and therefore, its current response $i_{C f}$ in this mode is characterized by a time constant $\tau=C_{f} R$ (where $R$ is the total resistance of the current flow path of $i_{C f}$ ).

$v_{Q L}$ equals to $V_{\text {panel }}$, and $\mathrm{L}_{\mathrm{kg}}$ and $\mathrm{C}_{\mathrm{r}}$ resonate again. $i_{V M}$ on the secondary side flows through $\mathrm{C}_{3}$ and the high-side diode $\mathrm{D}_{6}$. The operation moves to the next mode when $i_{L k g}$ and $i_{L m g}$ become the same value.

Mode $4\left(T_{3}<t \leq T_{s}\right)$ [Fig. 9(d)]: Both $i_{L k g}$ and $i_{L m g}$ linearly increase at the same rate, while no current flows on the secondary side, similarly to Mode 2 . The operation of the boost converter in this mode is identical to that in Mode 3. Turning on and off $\mathrm{Q}_{\mathrm{L}}$ and $\mathrm{Q}_{\mathrm{H}}$, respectively, brings the operation back to Mode 1 .

In summary, $\mathrm{D}_{5}$ and $\mathrm{D}_{6}$, which are connected in parallel with the shaded substring $\mathrm{PV}_{3}$, conduct, whereas other diodes

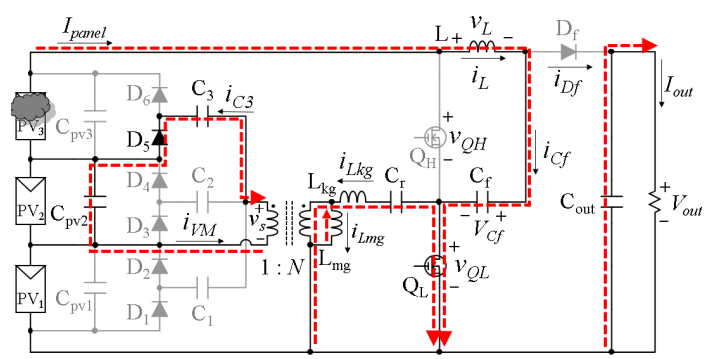

(a)

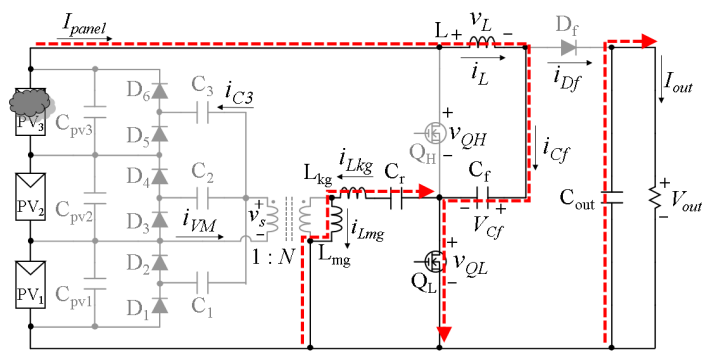

(b)

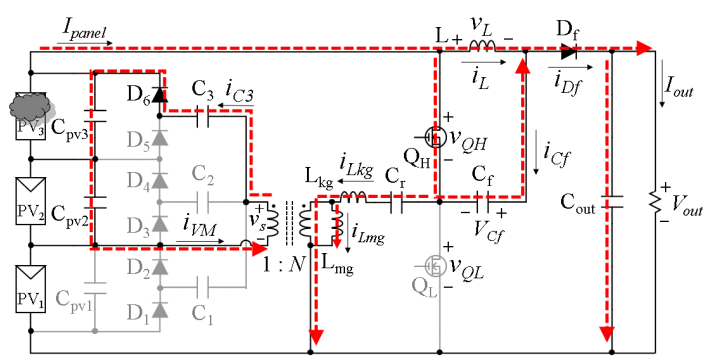

(c)

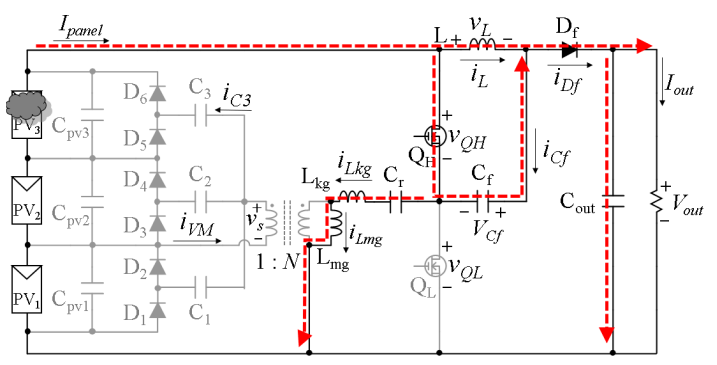

(d)

Fig. 9. Current flow paths in (a) Mode 1, (b) Mode 2, (c) Mode 3, and (d) Mode 4 


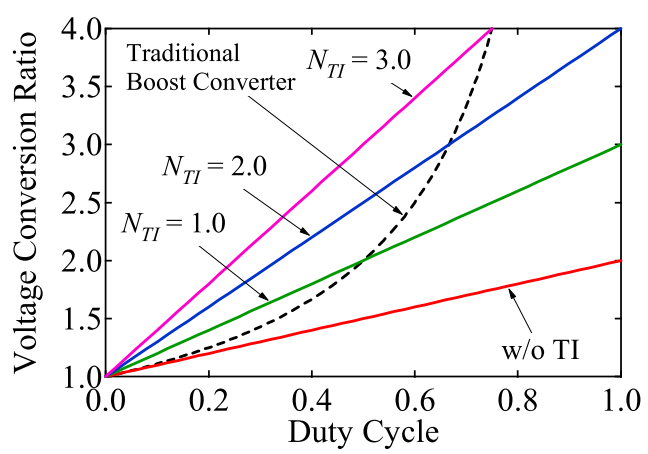

Fig. 10. Boost conversion ratios of proposed integrated converter as a function of $d$

are not in operation. Since an average current of $\mathrm{C}_{3}$ must be zero under steady-state conditions, an average current of $\mathrm{D}_{5}$ or $\mathrm{D}_{6}$ is identical to a current supplied to $\mathrm{PV}_{3}$ from the LLC-VM. The detailed power redistribution mechanism of the LLC-VM has been reported in the previous work ${ }^{(30)}$.

3.2 Voltage Conversion Ratio of PWM Boost Converter The theoretical boost conversion ratio can be derived from the volt-sec balance on L. Under steady-state conditions, $V_{C f}$ is determined by the following equation from the current paths in Modes 3 and 4 [see Figs. 9(c) and (d)];

$$
V_{C f}=V_{\text {out }}-V_{\text {panel }}
$$

From (1), $v_{L}$ is expressed as

$$
v_{L}= \begin{cases}V_{\text {panel }}-V_{C f}=2 V_{\text {panel }}-V_{\text {out }} & (\text { Mode 1,2) } \\ -V_{C f}=V_{\text {panel }}-V_{\text {out }} & (\text { Mode 3,4) }\end{cases}
$$

This equation implies that $\mathrm{L}$ can be miniaturized as $v_{L}$ is lower than that in a traditional boost converter, thanks to $V_{C f}$. The volt-sec balance on $\mathrm{L}$ yields the theoretical voltage boost conversion ratio, as

$$
\frac{V_{\text {out }}}{V_{\text {panel }}}=1+d
$$

where $d$ is the duty cycle of $\mathrm{Q}_{\mathrm{L}}$. This equation suggests the theoretical conversion ratio is between 1.0 and 2.0, which is narrower than that of traditional boost converters.

The voltage conversion ratio can be extended by the integrated converter with the TI [see Fig. 7(b)], as

$$
\frac{V_{\text {out }}}{V_{\text {panel }}}=1+d\left(1+N_{T I}\right)
$$

where $N_{T I}$ is the turn ratio of the TI. This equation suggests the TI extends the boost conversion ratio.

The voltage conversion ratios of the proposed integrated converter are shown in Fig. 10. Unlike the traditional boost converter with a boost ratio of $1 /(1-d)$, conversion ratios of the proposed converters are proportional to $d$. Although the proposed converter cannot cover a wide range (especially in the case without the $\mathrm{TI}$ ), the boost conversion ratio and range can be extended by employing the TI and enhancing the value of $N_{T I}$.

3.3 Miniaturization of Inductor in Boost Converter A charged or discharged energy $E_{C D}$ of an inductor in a

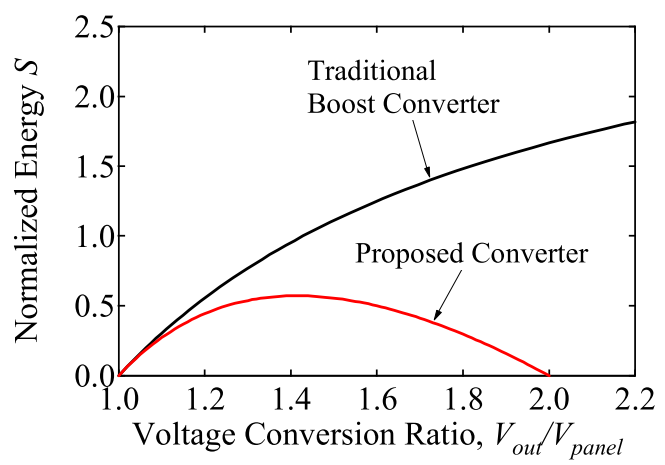

Fig. 11. Calculated normalized inductor energy $S$ as a function of voltage conversion ratio

single switching cycle is generalized in the form of

$$
E_{C D}=\int_{0}^{d T_{s}}\left|v_{L} i_{L}\right| d t=\int_{d T_{s}}^{T_{s}}\left|v_{L} i_{L}\right| d t \ldots \ldots \ldots \ldots
$$

where $v_{L}$ and $i_{L}$ are the voltage and current of an inductor. $E_{C D}$ reflects a ripple current of the inductor. Therefore, energy stored in the inductor $E_{L}$ can be expressed using a ripple current factor $\alpha$ (typically around $30 \%$ ), as

$$
E_{L}=\frac{E_{C D}}{\alpha}
$$

The normalized inductor energy, $S$, can be defined as

$$
S=\frac{E_{L}}{E_{\text {out }}}=\frac{E_{C D}}{\alpha V_{\text {out }} I_{\text {out }} T_{s}}
$$

where $E_{\text {out }}$ is the energy transferred to a load in a single switching cycle. In general, a volume of inductors is dependent on its stored energy, and hence, inductor volumes of different topologies can be quantitatively compared based on calculated values of $S$.

Under steady-state conditions, an average current of $\mathrm{C}_{\mathrm{f}}$ must be zero, and therefore, an average inductor current $I_{L}$ equals to the output current $I_{\text {out }}$;

$$
I_{L}=I_{\text {out }}
$$

It is noteworthy that $I_{L}$ of the proposed converter is lower than that in a traditional boost converter $\left[I_{L}=I_{\text {out }} /(1-d)\right]$. This is because a fraction of the output current or output power is processed by $\mathrm{C}_{\mathrm{f}}$, as can be seen in Figs. 9(c) and (d) $-i_{C f}$ flows toward the load.

Substitution of (2) and (8) into (5) and (7) yields

$$
S=\frac{d(1-d)}{\alpha(1+d)}
$$

Substituting (3) into (9) yields $S$ as a function of $V_{\text {out }} / V_{\text {panel }}$. The calculated $S$ of the proposed integrated converter is compared with that of a traditional boost converter, as shown in Fig. 11. $\alpha$ is 0.3 (i.e., 30\%). Although the voltage conversion ratio of the proposed converter is theoretically limited between 1.0 and 2.0, the proposed converter achieves lower $S$, suggesting the reduced inductor volume in the proposed integrated converter. The inductor miniaturization is attributed to that $\mathrm{C}_{\mathrm{f}}$ reduces $v_{L}$ and $I_{L}$ compared with those of traditional boost converters [see (2) and (8), respectively]. 


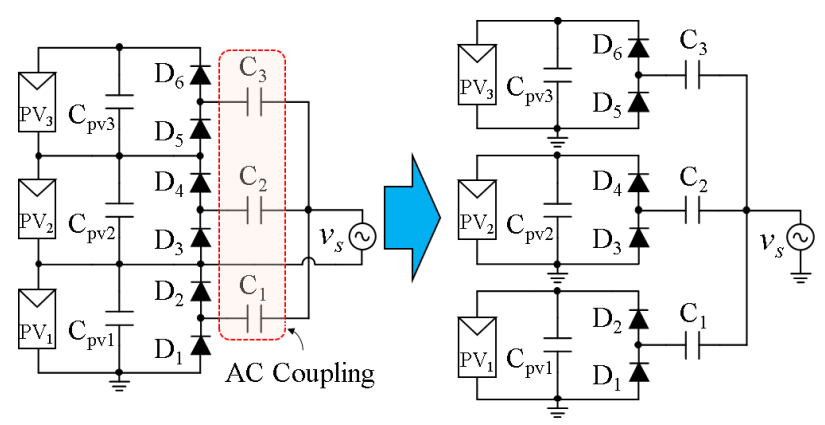

Fig. 12. Transformation of resonant voltage multiplier

3.4 LLC Voltage Multiplier The LLC-VM is powered by the panel and produces ac current that is transferred to the secondary side of the transformer. $d$ of the boost converter varies depending on conditions, but the characteristics of the DPP converter should desirably be unaffected by duty cycle variations.

As can be seen in Figs. 8 and 9, $i_{V M}$ and $i_{D}$ flow only in Modes 1 and 3 whose lengths are equal to half the resonant period. In Modes 2 and 4, on the other hand, the secondary side of the LLC-VM is essentially inactive [see Figs. 9(b) and (d)], and lengths of Modes 2 and 4 vary with duty cycle variations. In other words, duty cycle variations can be buffered in Modes 2 and 4.

In order for Modes 2 and 4 to exist, half the resonant period must be shorter than both $d T_{s}$ and $(1-d) T_{s}$, where $T_{s}$ is the switching period. Therefore, the switching frequency $f_{s}$ $\left(=1 / T_{s}\right)$ should satisfy the following equations

$$
f_{s} \leq\left\{\begin{array}{l}
2 d f_{r}=\frac{d}{\pi \sqrt{L_{k g} C_{r}}} \\
2(1-d) f_{r}=\frac{1-d}{\pi \sqrt{L_{k g} C_{r}}}
\end{array}\right.
$$

where $f_{r}$ is the resonant frequency. This equation suggests that $f_{s}$ should be determined with taking into account a variation range of $d$ at a given $f_{r}$.

The VM on the transformer secondary side is driven by ac voltage and current generated by the LLC resonant inverter. A square wave voltage $v_{s}$ with a peak-to-peak value of $V_{\text {panel }} / N$ is generated across the transformer secondary winding. Since coupling capacitors, $\mathrm{C}_{1}-\mathrm{C}_{3}$, are connected to the secondary winding, ac current components only pass through $\mathrm{C}_{1}-\mathrm{C}_{3}$ and flow toward substrings. A dc voltage equal to the peak-to-peak value of $v_{s}$ (i.e., $V_{\text {panel }} / N$ ) is outputted to each substring because each capacitor and diode pair (e.g., $\mathrm{C}_{1}, \mathrm{D}_{1}$, and $\mathrm{D}_{2}$ ) comprises a voltage doubler ${ }^{(30)}$.

Focusing only on the ac components yields the equivalent circuit, as shown in Fig. 12, in which all substrings, as well as diode rectifiers containing coupling capacitors, are separated and grounded. Since all substrings, as well as rectifiers, are connected in parallel, currents from the LLC-VM automatically and preferentially flow toward shaded substrings having the lowest voltage in the panel. This automatic current distribution equalizes the electrical characteristics of all substrings ${ }^{(30)}$.

\section{Experimental Results}

4.1 Prototype A $150-\mathrm{W}$ prototype of the proposed

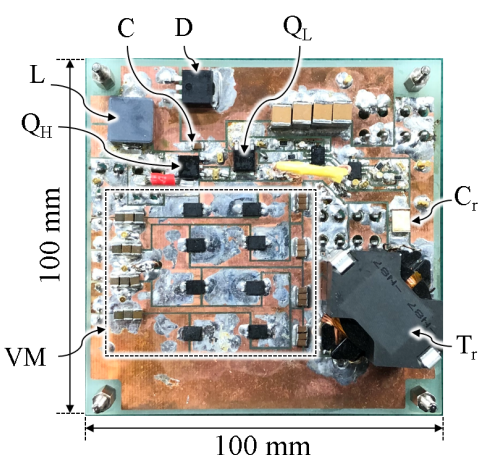

Fig. 13. Photograph of $150-\mathrm{W}$ prototype for four substrings

Table 1. Circuit components used for prototype

\begin{tabular}{cc}
\hline Component & Value \\
\hline $\mathrm{C}_{\mathrm{pvl}}-\mathrm{C}_{\mathrm{pv} 4}$ & Ceramic Capacitor, $300 \mu \mathrm{F}$ \\
$\mathrm{D}_{1}-\mathrm{D}_{8}$ & Schottky Barrier Diode, $V_{f}=0.30 \mathrm{~V}$ \\
$\mathrm{C}_{1}-\mathrm{C}_{4}$ & Ceramic Capacitor, $99 \mu \mathrm{F}$ \\
$\mathrm{C}_{\mathrm{f}}$ & Ceramic Capacitor, $33 \mu \mathrm{F}$ \\
$\mathrm{L}$ & Inductor, $47 \mu \mathrm{H}$ \\
$\mathrm{D}_{\mathrm{f}}$ & Schottky Barrier Diode, $V_{f}=0.40 \mathrm{~V}$ \\
$\mathrm{C}_{\text {out }}$ & Ceramic Capacitor, $176 \mu \mathrm{F}$ \\
$\mathrm{C}_{\mathrm{r}}$ & Film Capacitor, $220 \mathrm{nF}$ \\
Transformer & $N_{l}: N_{2}=12: 3$, \\
$\mathrm{Q}_{\mathrm{L}}, \mathrm{Q}_{\mathrm{H}}$ & $L_{k g}=1.54 \mu \mathrm{H}, L_{m g}=94.8 \mu \mathrm{H}$ \\
& FDD390N15A, $R_{D S(O N)}=33.5 \mathrm{~m} \Omega$ \\
\hline
\end{tabular}

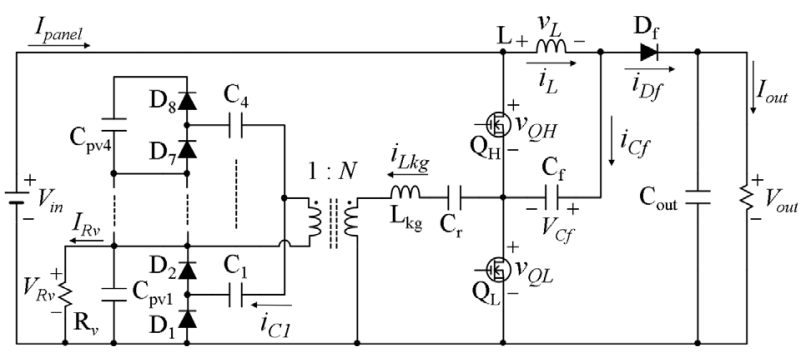

Fig. 14. Experimental setup for characteristic measurement

integrated converter that can supply $28 \mathrm{~W}$ for each shaded substring was built for four substrings connected in series, as shown in Fig. 13. Component values are listed in Table 1. For the integrated converter to operate with a duty cycle variation range of $0.2-0.8$ at $f_{s}=100 \mathrm{kHz}, f_{r}$ was designed to be $273 \mathrm{kHz}$, according to (10).

4.2 Measured Waveforms and Power Conversion Efficiency The experimental setup shown in Fig. 14 was employed to measure operation waveforms, power conversion efficiencies, and output characteristics of the LLC-VM of the prototype. An external power supply was used as the input voltage $V_{i n}$. A variable resistor $\mathrm{R}_{\mathrm{v}}$ was connected to the output of the VM to emulate the current flow paths under the partial shading condition where $\mathrm{PV}_{1}$ is shaded. The current of $\mathrm{R}_{\mathrm{v}}, I_{R v}$, corresponds to the current supplied to the shaded substring in practical use. Power conversion efficiencies and $V_{R v}$ were measured with varying $I_{R v}$ while the load power $P_{\text {out }}\left(=V_{\text {out }} I_{\text {out }}\right)$ was fixed to be 0,70 , or $140 \mathrm{~W}$ at $V_{\text {in }}=32 \mathrm{~V}$ and $d=0.5$.

Measured waveforms at $I_{R v}=1.0 \mathrm{~A}$ and $P_{\text {out }}=70 \mathrm{~W}$ are shown in Fig. 15. The good agreement with the theoretical ones shown in Fig. 8 demonstrated the proper operation of the prototype. 


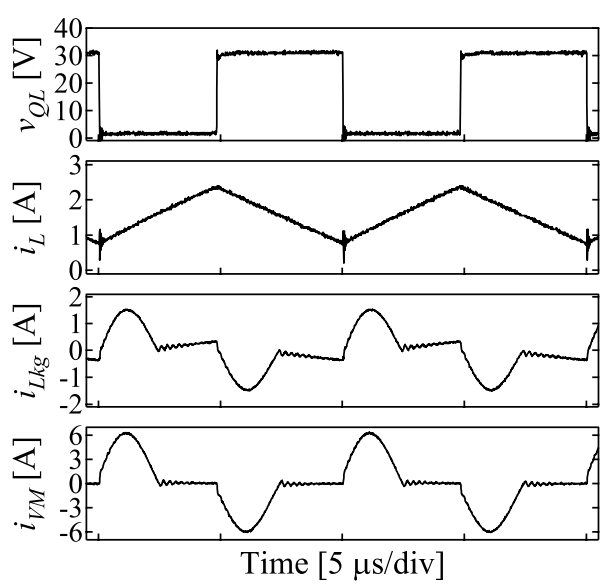

Fig. 15. Measured waveforms at $I_{R v}=1.0 \mathrm{~A}$ and $P_{\text {out }}=$ $70 \mathrm{~W}$

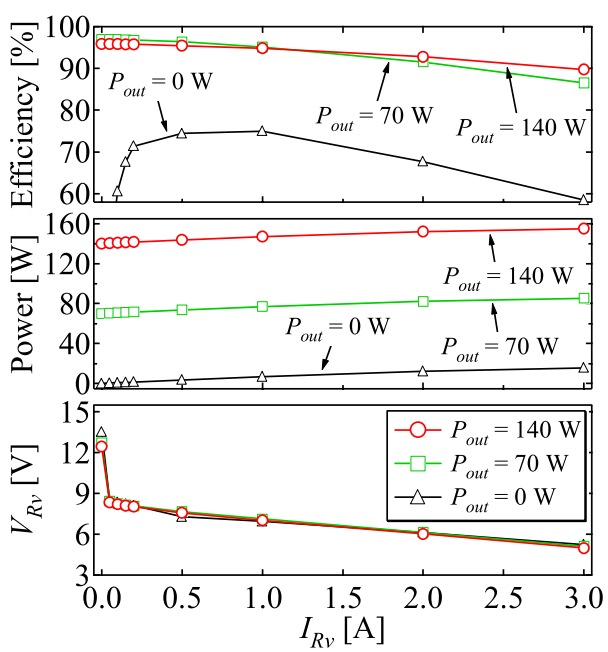

Fig. 16. Measured power conversion efficiencies and $V_{R v}$ as a function of $I_{R v}$ when $\mathrm{PV}_{1}$ was partially shaded

The measured power conversion efficiencies and $V_{R v}$ as a function of $I_{R v}$ are shown in Fig. 16. Measured trends of $V_{R v}$ were independent on $P_{\text {out }}$ (see the bottom panel in Fig. 16), suggesting that the output characteristics of the LLC-VM were independent on the operation of the boost converter.

The measured efficiencies increased with $P_{\text {out }}$, as shown in the top panel in Fig. 16. The case of $P_{\text {out }}=0 \mathrm{~W}$ was equivalent to the operation of the LLC-VM alone and the output power of the boost converter was zero. Therefore, the power conversion efficiency of the LLC-VM alone was lower than $75 \%$. Meanwhile, the case of $I_{R v}=0$ A corresponded to the operation of the boost converter alone, and therefore, the power conversion efficiency of the boost converter was approximately $96 \%$ at $P_{\text {out }}=70 \mathrm{~W}$ or $140 \mathrm{~W}$. These results suggested that the boost converter was more efficient than the LLC-VM. The most dominant loss factor in the LLC$\mathrm{VM}$ was the diode conduction loss as its output voltage of $V_{R v}$ was relatively low (lower than $8 \mathrm{~V}$ ). Another major loss factor was the copper loss of the transformer because of the relatively large RMS value of $i_{V M}$, which flows only in Modes 1 and 3 (see Fig. 8).

4.3 Laboratory Testing Emulating Partial Shading Condition An experimental equalization test using solar array simulators (E4361A, Keysight Technologies) in our

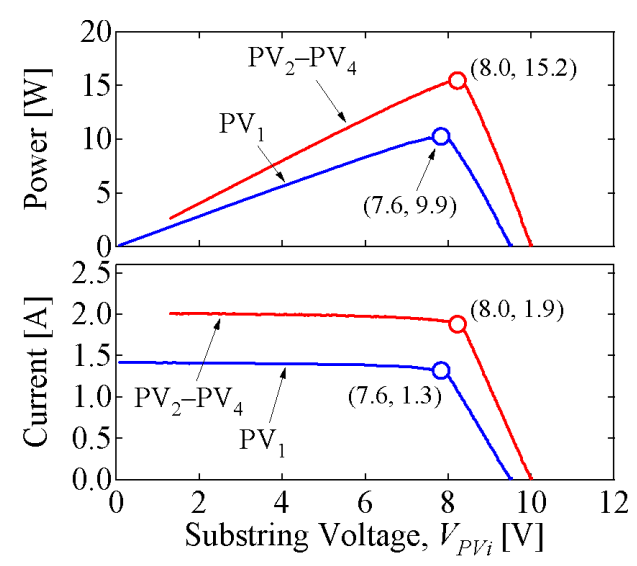

(a)

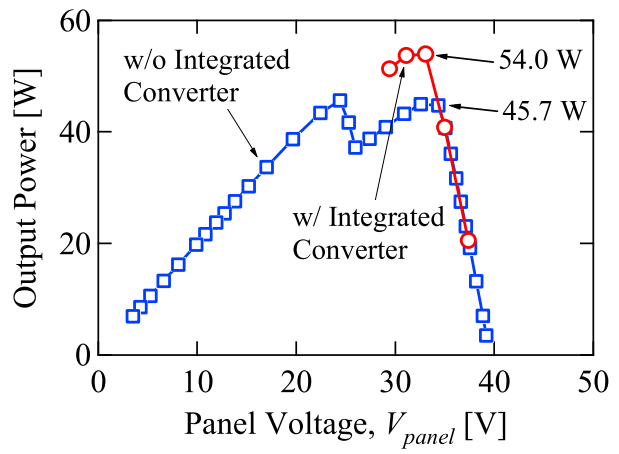

(b)

Fig. 17. Experimental results of laboratory testing. (a) Individual substring characteristics. (b) Panel characteristics with/without integrated converter

laboratory was performed emulating the partial shading condition where $\mathrm{PV}_{1}$ was shaded. Individual substring characteristics used for the laboratory experiment are shown in Fig. 17(a) - the characteristics were swept using an electronic load and measured by a data logger (NR-500, KEYENCE), and MPPs are highlighted with markers. If all substrings were to be able to operate at each MPP in this condition, the maximum power of the panel as a whole would have been $55.5 \mathrm{~W}$. $V_{\text {out }}$ was fixed to be $48 \mathrm{~V}$ by an electronic load operating in a constant voltage mode, while $d$ was manually varied in the range of $0.3-0.7$ to sweep panel characteristics. A bypass diode was connected in parallel with each substring to compare panel characteristics with/without the integrated converter.

The measured $P-V$ characteristics of the panel with/ without the integrated converter are shown in Fig. 17(b). Without the integrated converter, two MPPs (a global and local MPPs) on the $P-V$ characteristics were observed, and the maximum power was $45.7 \mathrm{~W}$. With the integrated converter, conversely, the local MPP disappeared, and the maximum power increased to as high as $54.0 \mathrm{~W}$, corresponding to $18.2 \%$ improvement in power yield. The overall efficiency was approximately $97.3 \%(=54.0 / 55.5 \mathrm{~W})$. The results demonstrated that the proposed converter could eliminate partial shading issues.

4.4 Field Testing Emulating Characteristic Mismatch Condition The field testing was performed using two flexible panels (CVFM-0580T1-WH, Clean Venture 21), each consisting of two substrings, in Hitachi, Japan, at 15:00 


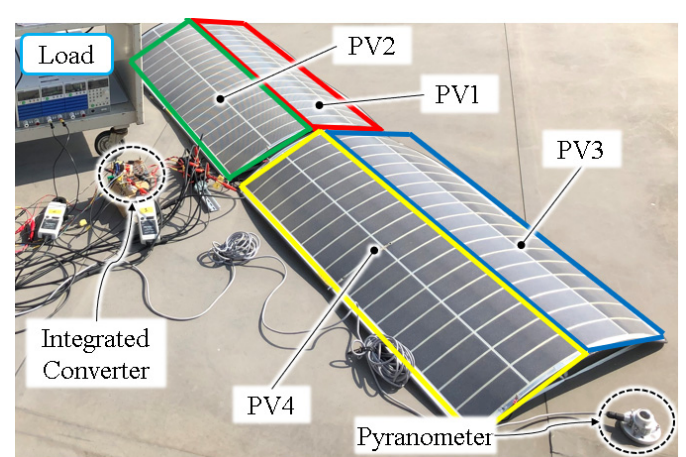

Fig. 18. Experimental setup of field testing using flexible PV panels

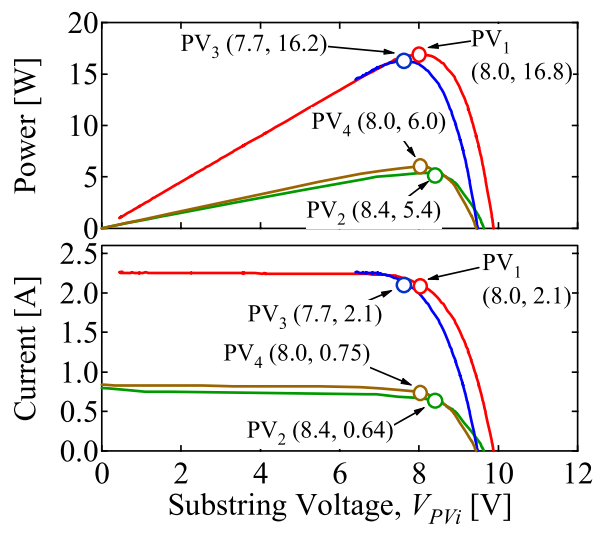

(a)

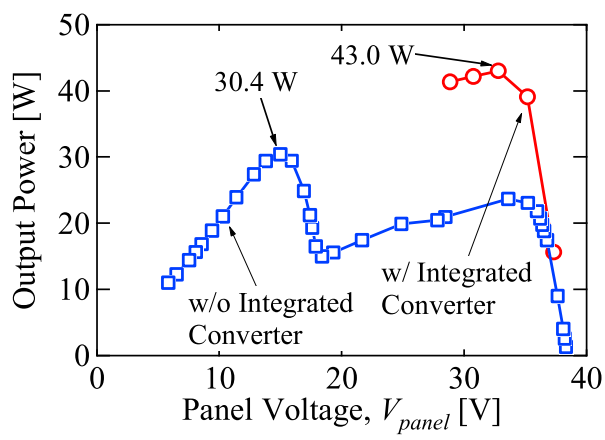

(b)

Fig. 19. Experimental results of field testing. (a) Individual substring characteristics. (b) Panel characteristics with/without integrated converter

on April 2019, as shown in Fig. 18. The flexible panels were intentionally bent in order to roughly emulate a mismatched irradiance condition on PV panels mounted on a PHEV's roof. The solar irradiance was measured using a pyranometer (ES-602, EKO), and the average solar irradiance in the field testing was $495 \mathrm{~W} / \mathrm{m}^{2}$. Similar to the laboratory testing, $V_{\text {out }}$ was fixed to be $48 \mathrm{~V}$, and $d$ was varied in the range of 0.3-0.7.

Measured individual substring characteristics in the field testing are shown in Fig. 19(a). The mismatched irradiance on the flexible panels resulted in severe characteristic mismatch, and the ideal maximum power was $44.6 \mathrm{~W}$ in this condition.

The measured $P-V$ characteristics of the panel with/ without the integrated converter are compared in Fig. 19(b). The maximum power without the integrated converter was merely $30.4 \mathrm{~W}$ that was equivalent to the overall efficiency of
$68.2 \%(=30.4 / 44.6 \mathrm{~W})$. With the integrated converter, the local MPP successfully disappeared, and the maximum power reached as high as $43.0 \mathrm{~W}$. This result corresponds to $41.4 \%$ improvement in power yield and the overall efficiency of approximately $96 \%(=43.0 / 44.6 \mathrm{~W})$. Thus, the proposed integrated converter precluded the negative influences of the characteristic mismatch due to uneven irradiance on PV substrings in the field testing.

\section{Conclusions}

The PWM boost converter integrating an LLC-VM-based DPP converter has been proposed in this paper. This converter can not only boost the panel voltage by PWM control but also automatically supply power to the shaded substrings without feedback control. The proposed converter not only simplifies the system by integrating two converters into a single unit but also achieves the reduced switch count as well as inductor miniaturization in comparison with a conventional system using a boost converter and DPP converter separately.

Laboratory and field testing using the prototype was performed emulating partial shading and irradiance mismatch conditions. The proposed integrated converter eliminated local MPPs and enhanced the maximum power by $18.2 \%$ and $41.4 \%$ in the laboratory and field tests, respectively, demonstrating its efficacy.

\section{References}

( 1 ) S.M. MacAlpine, R.W. Erikson, and M.J. Brandemuehl: "Characterization of power optimizer potential to increase energy capture in photovoltaic systems operating under nonuniform conditions", IEEE Trans. Power Electron., Vol.28, No.6, pp.2936-2945 (2012)

( 2 ) H. Sato, T. Nakane, and M. Uno: "DPP converter using LLC resonant voltage multiplier with a voltage divider for curved solar roof of PHEVs", in Proc. IEEE 18th Int. Conf. Power Electron. Motion Control (PEMC), pp.101-1085 (2018)

( 3 ) H. Jeong, H. Lee, Y.C. Liu, and K.A. Kim: "Review of differential power processing converters techniques for photovoltaic applications", IEEE Trans. Energy Conversion, Vol.34, No.1, pp.351-360 (2019)

( 4 ) H.J. Bergveld, D. Büthker, C. Castello, T. Doorn, A.D. Jong, R.V. Otten, and K.D. Waal: "Module-level dc/dc conversion for photovoltaic systems: the delta-conversion concept", IEEE Trans. Power Electron., Vol.28, No.4, pp.2005-2013 (2013)

( 5 ) M.S. Zaman, Y. Wen, R. Fernandes, B. Buter, T. Doorn, M. Dijkstra, H.J. Bergveld, and O. Trescases: "A cell-level differential power processing IC for concentrating-PV systems with bidirectional hysteretic current-mode control and closed-loop frequency regulation", IEEE Trans. Power Electron., Vol.30, No.12, pp.7230-7244 (2015)

( 6 ) P.S. Shenoy, K.A. Kim, B.B. Johnson, and P.T. Krein: "Differential power processing for increased energy production and reliability of photovoltaic systems", IEEE Trans. Ind. Power Electron., Vol.28, No.6, pp.2968-2979 (2013)

( 7 ) S. Qin, S.T. Cady, A.D.D. García, and R.C.N. Podgurski: "A distributed approach to maximum power point tracking for photovoltaic submodule differential power processing", IEEE Trans. Power Electron., Vol.30, No.4, pp.2024-2040 (2015)

( 8 ) F. Wang, T. Zhu, F. Zhuo, and H. Yi: "An improved submodule differential power processing-based PV system with flexible multi-MPPT control", IEEE J. Emerging Selected Topics, Vol.6, No.1, pp.94-102 (2018)

( 9 ) L.F.L. Villa, X. Pichon, F.S. Ardelibi, B. Raison, J.C. Crebier, and A. Labonne: "Toward the design of control algorithms for a photovoltaic equalizer: choosing the optimal switching strategy and the duty cycle", IEEE Trans. Power Electron., Vol.29, No.3, pp.1447-1460 (2014)

(10) T. Shimizu, M. Hirakata, T. Kamezawa, and H. Watanabe: "Generation control circuit for photovoltaic modules”, IEEE Trans. Power Electron., Vol.16, No.3, pp.293-300 (2001)

(11) T. Shimizu, O, Hashimoto, and G. Kimura: "A novel high-performance 
utility-interactive photovoltaic inverter system", IEEE Trans. Power Electron., Vol.18, No.2, pp.704-711 (2003)

(12) J.T. Stauth, M.D. Seeman, and K. Kesarwani: "Resonant switched-capacitor converters for sub-module distributed photovoltaic power management", IEEE Trans. Power Electron., Vol.28, No.3, pp.1189-1198 (2013)

(13) A.H. Chang, A.T. Avestruz, and S.B. Leeb: "Capacitor-less photovoltaic celllevel power balancing using diffusion charge redistribution", IEEE Trans. Power Electron., Vol.30, No.2, pp.537-546 (2015)

(14) A. Blumenfeld, A. Cervera, and M.M. Peretz: "Enhanced differential power processor for PV systems: resonant switched-capacitor gyrator converter with local MPPT", IEEE J. Emerging Selected Topics Power Electron., Vol.2, No.4, pp.883-892 (2014)

(15) M. Uno and A. Kukita: "PWM converter integrating switched capacitor converter and series-resonant voltage multiplier as equalizers for photovoltaic modules and series-connected energy storage cells for exploration rovers", IEEE Trans. Power Electron., Vol.32, No.11, pp.8500-8513 (2017)

(16) Z. Qiu and K. Sun: "A photovoltaic generation system based on wide voltagegain DC-DC converter and differential power processors for DC microgrids", Chinese J. Electrical Engineering, Vol.3, No.1, pp.84-95 (2017)

(17) M. Gokdaga, M. Akbabab, and O. Gulbudakc: "Switched-capacitor converter for PV modules under partial shading and mismatch conditions", Solar Energy, Vol.170, pp.723-731 (2018)

(18) M. Uno, Y. Saito, M. Yamamoto, and S. Urabe: "PWM switched capacitorbased cell-level power balancing converter utilizing diffusion capacitance of photovoltaic cells", IEEE Trans. Power Electron., Vol.34, No.11, pp.1067510687 (2019)

(19) M. Uno, M. Yamamoto, H. Sato, and S. Oyama: "Modularized differential power processing architecture based on switched capacitor converter to virtually unify mismatched photovoltaic panel characteristics", IEEE Trans. Power Electron., Vol.35, No.2, pp.1563-1575 (2020)

(20) C. Olalla, D. Clement, M. Rodríguez, and D. Makisimović: "Architectures and control of submodule integrated dc-dc converters for photovoltaic applications", IEEE Trans. Power Electron., Vol.28, No.6, pp.2980-2997 (2013)

(21) Y. Levron, D.R. Clement, B. Choi, C. Olalla, and D. Maksimovic: "Control of submodule integrated converters in the isolated-port differential powerprocessing photovoltaic architecture", IEEE J. Emerging Selected Topics Power Electron., Vol.2, No.4, pp.821-832 (2014)

(22) R. Bell and R.C.N.P. Podgurski: "Decoupled and distributed maximum power point tracking of series-connected photovoltaic submodules using differential power processing", IEEE J. Emerging Selected Topics Power Electron., Vol.3, No.4, pp.881-891 (2015)

(23) C. Olalla, C. Deline, D. Clement, Y. Levron, M. Rodríguez, and D. Makisimović: "Performance of power limited differential power processing architectures in mismatched PV systems", IEEE Trans. Power Electron., Vol.30, No.2, pp.618-631 (2015)

(24) G. Chu, H. Wen, L. Jiang, Y. Hu, and X. Li: "Bidirectional flyback based isolated-port submodule differential power processing optimizer for photovoltaic applications", Solar Energy, Vol.158, pp.929-940 (2017)

(25) Y.T. Jeon, H. Lee, K.A. Kim, and J.H. Park: "Least power point tracking method for photovoltaic differential power processing systems", IEEE Trans. Power Electron., Vol.32, No.3, pp.1941-1951 (2017)

(26) Y.T. Jeon and J.H. Park: "Unit-minimum least power point tracking for the optimization of photovoltaic differential power processing systems", IEEE Trans. Power Electron., Vol.34, No.1, pp.311-324 (2019)

(27) J. Du, R. Xu, X. Chen, Y. Li, and J. Wu: "A novel solar panel optimizer with self-compensation for partial shadow condition", in Proc. IEEE Applied Power Electron. Conf. Expo. (APEC), pp.92-96 (2013)

(28) M. Uno and A. Kukita: "Single-switch voltage equalizer using multi-stacked buck-boost converters for partially-shaded photovoltaic modules", IEEE Trans. Power Electron., Vol.30, No.6, pp.3091-3105 (2015)

(29) M. Uno and A. Kukita: "Current sensorless equalization strategy for a singleswitch voltage equalizer using multistacked buck-boost converters for photovoltaic modules under partial shading", IEEE Trans. Ind. Appl., Vol.53, No.1, pp.420-429 (2017)

(30) M. Uno and A. Kukita: "Two-switch voltage equalizer using an LLC resonant inverter and voltage multiplier for partially-shaded series-connected photovoltaic modules", IEEE Trans. Ind. Appl., Vol.51, No.2, pp.1587-1601 (2015)

(31) M. Uno and A. Kukita: "Single-switch single-magnetic PWM converter integrating voltage equalizer for partially-shaded photovoltaic modules in standalone applications", IEEE Trans. Power Electron., Vol.33, No.2, pp.12591270 (2018)

(32) S.R. Sanders, E. Alon, H.P. Le, M.D. Seeman, M. Jhon, and V.W. Ng: "The road to fully integrated dc-dc conversion via the switched-capacitor approach", IEEE Trans. Power Electron., Vol.28, No.9, pp.4146-4155 (2013)

(33) M. Uno and A. Kukita: "PWM switched capacitor converter with switchedcapacitor-inductor cell for adjustable high step-down voltage conversion", IEEE Trans. Power Electron., Vol.34, No.1, pp.425-437 (2019)

(34) A.M.S.S. Andrade, E. Mattos, L. Schuch, H.L. Hey, and M.L.S. Martins: "Synthesis and comparative analysis of very high step-up DC-DC converters adopting coupled-inductor and voltage multiplier cells", IEEE Trans. Power Electron., Vol.33, No.7, pp.5880-5897 (2018)

(35) S. Chen, L. Zhou, Q. Luo, W. Gao, Y. Wei, P. Sun, and X. Du: "Research on topology of the high step-up boost converter with coupled inductor", IEEE Trans. Power Electron., Vol.34, No.11, pp.10733-10745 (2019)

Masatoshi Uno (Member) received the B.E. degree in electronics engineering and the M.E. degree in electrical engineering from Doshisha University, Kyoto, Japan, and the Ph.D. degree in space and astronautical science from the Graduate University for Advanced Studies, Hayama, Japan, in 2002, 2004, and 2012, respectively. In 2004, he joined the Japan Aerospace Exploration Agency, Sagamihara, Japan, where he developed spacecraft power systems including battery, photovoltaic, and fuel cell systems. Since 2014, he has been with Ibaraki University as an associate professor. His research interests include dc-dc converters and inverters for renewable energy systems, life evaluation for supercapacitors and lithium-ion batteries, and development of fuel cell systems. Dr. Uno received the Isao Takahashi Power Electronics Award in 2018.

Yusuke Sasaki (Student Member) received the B.E. degree in elec-

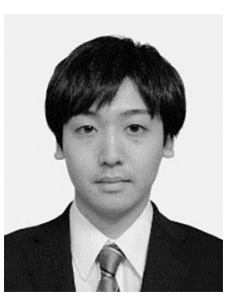
trical engineering from Ibaraki University, Hitachi, Japan, in 2019. He is currently working toward the M.E. degree in electrical engineering in the Graduate School of Science and Engineering, Ibaraki University. His research interests include switching converters for photovoltaic systems. 